\title{
Dynamic Temperature and Pressure Measurements in the Core of a Propulsion Engine
}

\author{
Bill Schuster $^{1}$ and Grant Gordon ${ }^{2}$ \\ Honeywell Aerospace, Phoenix, AZ, 85034 \\ Lennart S. Hultgren ${ }^{3}$ \\ NASA Glenn Research Center, Cleveland, $\mathrm{OH}, 44135$
}

\begin{abstract}
Dynamic temperature and pressure measurements were made in the core of a TECH977 propulsion engine as part of a NASA funded investigation into indirect combustion noise. Dynamic temperature measurements were made in the combustor, the inter-turbine duct, and the mixer using ten two-wire thermocouple probes. Internal dynamic pressure measurements were made at the same locations using piezoresistive transducers installed in semi-infinite coils. Measurements were acquired at four steady state operating conditions covering the range of aircraft approach power settings. Fluctuating gas temperature spectra were computed from the thermocouple probe voltage measurements using a compensation procedure that was developed under previous NASA test programs. A database of simultaneously acquired dynamic temperature and dynamic pressure measurements was produced. Spectral and cross-spectral analyses were conducted to explore the characteristics of the temperature and pressure fluctuations inside the engine, with a particular focus on attempting to identify the presence of indirect combustion noise.
\end{abstract}

\section{Nomenclature}

$\begin{array}{ll}S W & =\text { small wire thermocouple } \\ L W & =\text { large wire thermocouple } \\ C F & =\text { combustor forward probe } \\ C A & =\text { combustor aft probe } \\ L F & =\text { turbine duct forward probe } \\ L A & =\text { turbine duct aft probe } \\ M X & =\text { mixer probe } \\ N F C & =\text { corrected fan speed }\end{array}$

\section{Introduction}

ORE noise generated by propulsion engines has received increased interest in recent years as an impotion
contributor to aircraft noise. In particular, combustion noise has become a progressively more significant
source at approach power settings for high bypass ratio engines, where combustion noise is not masked by jet
Two main sources of combustion noise have historically been considered. The first is direct combustion
where random pressure fluctuations are directly produced by the unsteady heat release generated by the turb
combustion process. These pressure fluctuations excite acoustic waves that propagate downstream through
engine core. The second is indirect combustion noise, where random pressure fluctuations are indirectly prod
when entropy fluctuations generated by the turbulent combustion process convect through mean flow vel
gradients. The pressure fluctuations generated by this coupling between entropy and pressure disturbances
excite acoustic waves that propagate downstream through the engine core. Mean flow gradients are especia
pronounced in the turbine stages. The interaction of entropy fluctuations with the first stage high pressure tur

${ }^{1}$ Staff Engineer, Installation Aerodynamics \& Acoustics, $111 \mathrm{~S}$ S. 34th St. M/S 503-428, AIAA Senior Member.
${ }^{2}$ Staff Engineer, Advanced Technology, 111 S. 34th St. M/S 503-428.
${ }^{3}$ Acoustics Branch, 21000 Brookpark Rd MS 54-3, AIAA Associate Fellow. 
nozzle is of particular interest for indirect combustion noise. Numerous challenges have impeded a complete understanding of the direct and indirect combustion noise generating processes. From an empirical standpoint, it is difficult to acquire dynamic temperature and pressure measurements in the hostile interior of an engine combustor. From a data analysis standpoint, it is challenging to separate the acoustic contributions from the direct and indirect noise mechanisms, and to separate hydrodynamic fluctuations from acoustic fluctuations. Sophisticated signal processing methods are required to dissect the individual contributions to the broadband combustion noise. Finally, from a simulation standpoint, it is difficult to model the complex stochastic acoustic processes that occur throughout the engine core. Theoretical or computational models must address the strong variations in the geometry and mean flow, the effects associated with stationary and rotating blade rows, and the transmission and reflection effects created by impedance changes. This paper focuses on the empirical aspects of the problem and describes dynamic temperature and pressure measurements that were simultaneously acquired in the core of a Honeywell TECH977 propulsion engine under a NASA funded test program. A database of measurements was acquired to support a more thorough investigation of indirect combustion noise.

\section{Dynamic Temperature and Pressure Probes}

Measuring fluctuating temperatures in the core of a turbine engine is a challenging task due a combination of delicate instrumentation, hostile flow conditions, and limited accessibility. In this program, dynamic temperature measurements were made using two-wire thermocouple probes. These probes feature two thin thermocouple wires of different diameters placed in close proximity. The two wires respond differently to temperature fluctuations due to their difference in mass. Knowledge of their convective and conductive frequency response characteristics can be used to infer the fluctuating gas temperature from the measured fluctuating wire temperatures. Two-wire thermocouple probes have been used for many decades to measure fluctuating temperatures downstream of combustors. ${ }^{1,2}$ The design and operation of two-wire thermocouple probes, along with data reduction procedures, have been well developed and refined during several NASA test efforts. ${ }^{3-7}$ In those programs, a theoretical model was developed that accounts for the convective heat transfer between the gas stream and the probe wires, and for the conductive heat transfer within probe wires and wire supports. The model contains an unknown, operating point dependent, in-situ heat transfer calibration coefficient, which is determined using the measured transfer function between the large and small wires. A computer code was written to compute the theoretical transfer functions using knowledge of the probe geometric and material characteristics, compute the measured transfer function, determine the calibration coefficient, and use the calibrated model to compute the fluctuating temperatures. The software takes the raw voltage signals measured by the two wires, converts the wire voltages to wire temperatures using the appropriate thermocouple coefficients, and calculates compensation spectra that can be applied to the measured small or large wire dynamic temperature spectra to obtain compensated temperature spectra, i.e. the fluctuating temperature spectra of the actual gas stream.

The probe design used in this test is very similar to the probe designs used in the previous NASA test programs. The probes were constructed using Type B thermocouple wires, in order to survive the very high temperatures encountered in the combustor. A photo of the sensing end of the probe is shown in Figure 1. On the upstream side is a 0.003 " diameter beadless thermocouple junction, consisting of a Platinum- $70 \% /$ Rhodium- $30 \%$ wire element that is laser welded (at the center) to a Platinum-94\%/Rhodium-6\% wire element. Slightly downstream of the small wire and radially offset is a $0.010^{\prime \prime}$ diameter thermocouple junction constructed using the same materials. The small and large wires are welded to $0.020^{\prime \prime}$ diameter support wires of the corresponding material type. The support wires are installed in a six-hole alumina rod and sealed in place with a ceramic potting compound. The support wires run down the length of a 15" long ceramic stick and terminate at a connector for attachment to data system cables. The ceramic stick is installed inside an Inconel tube that provides structural support, except for the last $2.5^{\prime \prime}$ of the stick which extends into the flowpath. In addition to the two fine wire thermocouples, a reference Type B thermocouple was installed at the base of one of the remaining holes to serve as a cross-check of the mean temperature during operation. 
Platinum-70\%/Rhodium-30\% Wires

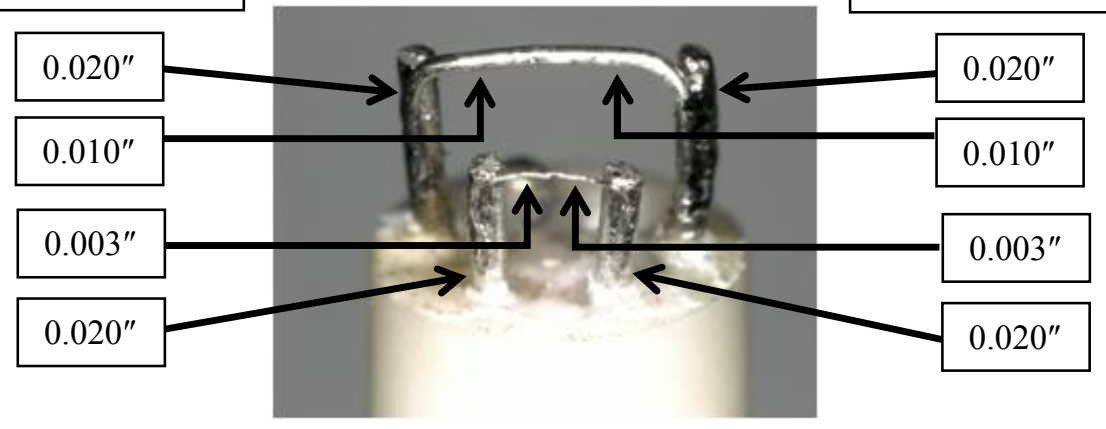

Figure 1. View of the Sensing End of the Two-Wire Type B Thermocouple Probe.

Dynamic pressure measurements inside the engine were made using piezo-resistive transducers installed in semiinfinite coils. At each measurement location, a 36" long $0.125^{\prime \prime}$ diameter sensing tube was installed flush to the outer wall of the duct. The length of the sensing line was chosen to enable the pressure transducers to be installed on the outside of the engine. The sensing line is connected to a tee, where a XTE190-10D 10-psi differential style transducer is tapped flush into the wall of the tube. On the opposite end of the tee is a $40 \mathrm{ft}$ long semi-infinite coil that serves to damp the acoustic waves so that the reflected signal does not interfere with the signal at the Kulite measurement location. A photo of a typical semi-infinite Kulite probe is shown in Figure 2. For the probes that were installed in the combustor and inter-turbine ducts, the terminating ends of the semi-infinite coils were connected to a nitrogen supply. Separate supply manifolds were used for the combustor and inter-turbine duct probes. A very small flow of nitrogen gas was supplied to keep the transducers cool and to maintain a more uniform temperature in the sensing lines. The nitrogen supplies for the combustor and inter-turbine probes were regulated by delta-p valves that utilized the local mean pressures in the combustor and inter-turbine duct, respectively, to control the supply pressure.

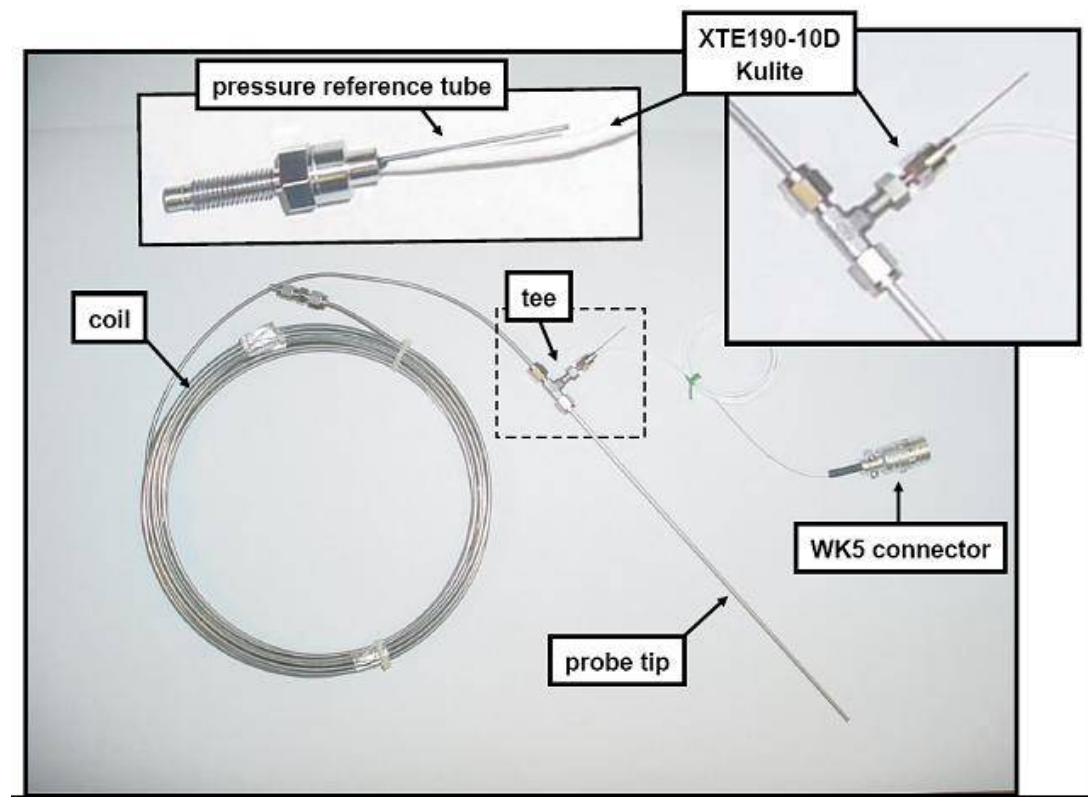

Figure 2. Example of a Semi-Infinite Coil Dynamic Pressure Probe. 


\section{Engine Instrumentation}

The TECH977 engine, shown in Figure 3, was used as the test vehicle for this program. This is a propulsion engine in the $7000 \mathrm{lb}$ thrust class with a 2 stage high pressure turbine (HPT) and a 3 stage low pressure turbine (LPT). Ten dynamic temperature probes were installed in the core of the engine, at the locations shown schematically in Figure 4. Four probes were installed in the combustor upstream of the HPT in order to quantify the magnitude of the temperature fluctuations that convect into the HPT. The probes were grouped into two pairs, with each pair consisting of a forward probe and an aft probe. The intent of the forward and aft probe combination was to enable the calculation of the convection speeds of the fluctuating temperature eddies. One pair of probes was oriented at approximately $90^{\circ}$ aft looking forward (ALF), and roughly centered in between two upstream fuel nozzles. These probes were spaced 2" apart axially, with the forward probe offset slightly in the azimuthal direction so that its wake would not impinge upon the downstream probe. The other pair of probes was positioned at approximately $260^{\circ} \mathrm{ALF}$, roughly in line with an upstream fuel nozzle, and spaced 1.5" apart axially. The two aft combustor probes were positioned at the same axial station.

Four probes were installed in the inter-turbine duct upstream of the LPT to quantify the magnitude of the temperature fluctuations that convect into the LPT. As in the combustor, the probes were grouped into two pairs. One pair was positioned at approximately $90^{\circ}$ ALF, with an axial spacing of $1.3^{\prime \prime}$ between the forward and aft probes, and with the forward probe offset slightly in the azimuthal direction to avoid wake impingement. The other pair was positioned at approximately $260^{\circ} \mathrm{ALF}$, with an axial spacing of $1.0^{\prime \prime}$. Finally, downstream of the LPT, at the entrance to the mixer nozzle, single probes were placed at the $90^{\circ}$ and $260^{\circ}$ locations to measure the magnitudes of the residual temperature fluctuations that convect through the exhaust nozzle. The sensing ends of the all of the temperature probes (when deployed) were positioned roughly in the middle of the annular duct passage to avoid any influences of the end walls. Measurements were acquired at a single radial immersion depth; no radial or azimuthal surveys were performed. In order to maximize the life of the temperature probes, a pneumatically driven actuator system was used to deploy all of the probes into the engine core. The probes were retracted during engine startup and shutdown and deployed during data collection.

Ten dynamic pressure probes were installed at locations adjacent to the temperature probes. The ends of the pressure sensing tubes were mounted flush to the outer wall of the annular duct. Thus the pressure measurements are not made in the middle of the annulus next to the deployed temperature probe, but rather at the corresponding wall location. However, this did not pose any limitations on the measurement, because only the lowest order radial acoustic modes can propagate in the annular ducts at the frequencies of interest in this study. The axial spacing (and small tangential offset) of the upstream and downstream pressure probes in the combustor and inter-turbine duct were the same as the spacing of the corresponding pair of temperature probes, at both the $90^{\circ}$ and $260^{\circ}$ locations. Four additional dynamic pressure probes were installed in the forward portion of the combustor to serve as a crosscheck of the circumferential mode content, which had been measured previously during the NASA-sponsored Engine Validation of Noise and Emissions Reduction Technologies (EVNERT) program. ${ }^{8}$ In addition to the internal pressure measurements, two external ground microphones were placed roughly 20 feet from the nozzle exit at $90^{\circ}$ and $120^{\circ}$. Far field noise measurements were not acquired during this test program, but extensive measurements were previously acquired during the NASA EVNERT program on this same engine. ${ }^{9}$ 


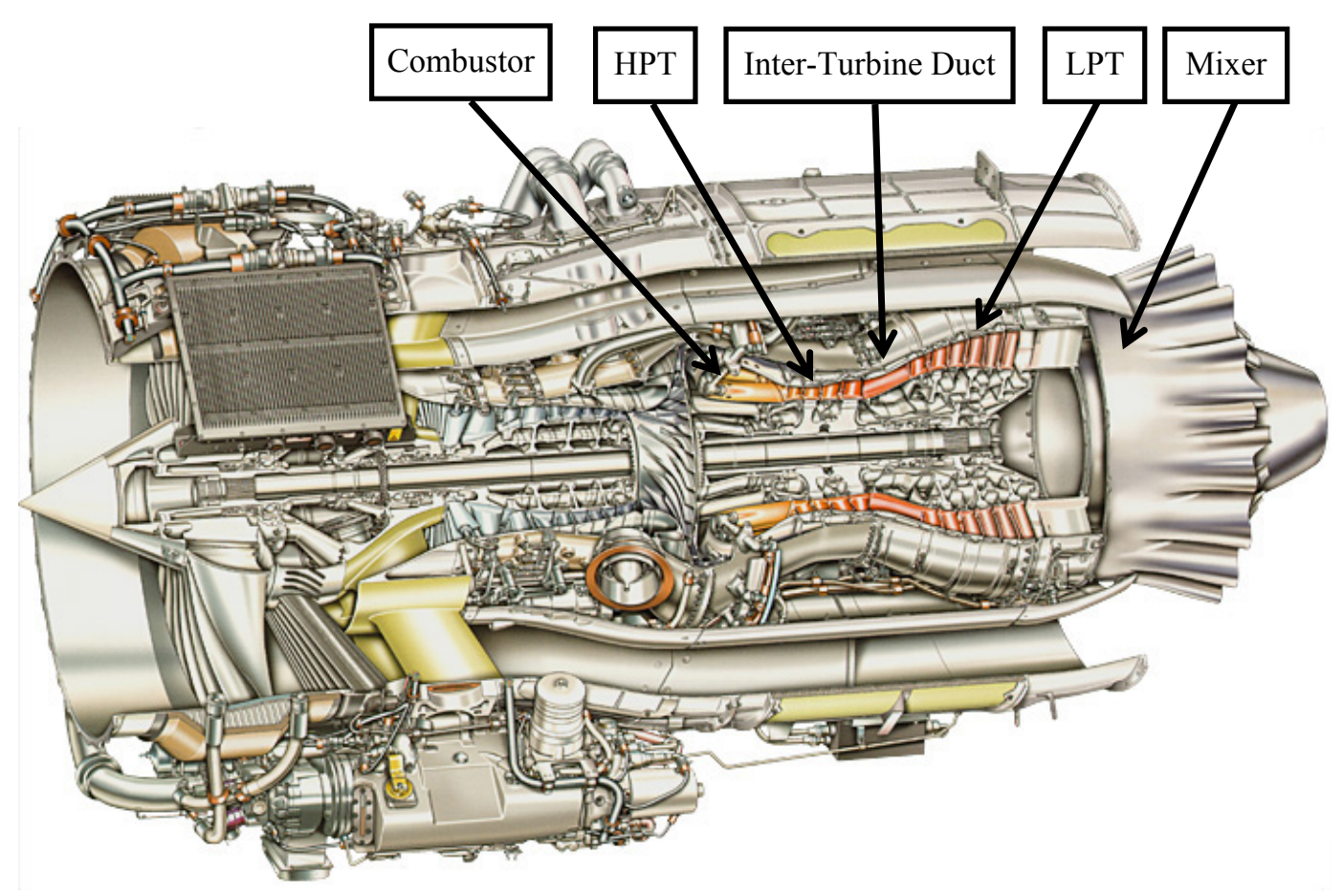

Figure 3. View of the Instrumentation Locations on the TECH977 Engine.

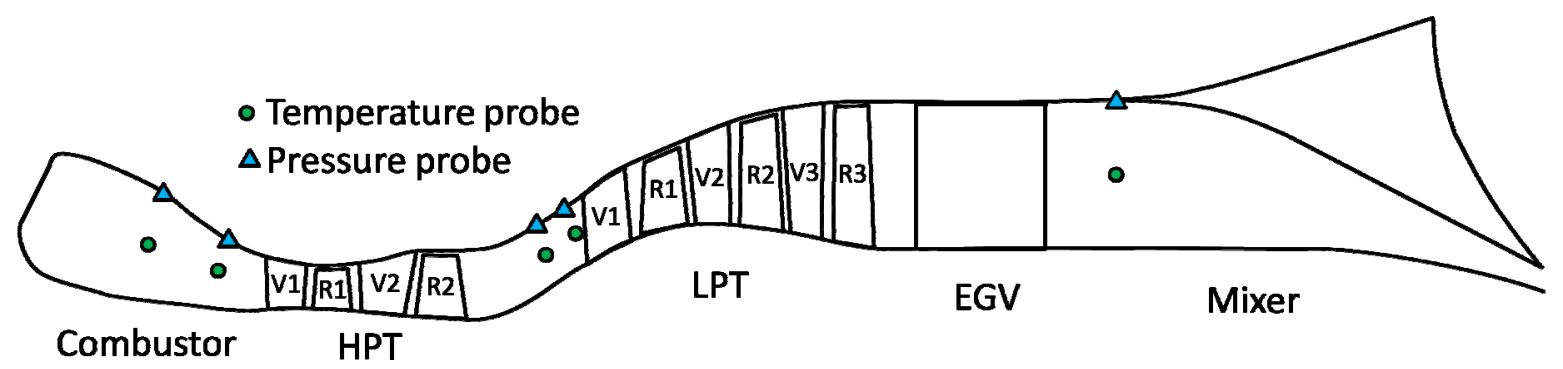

Figure 4. Locations of Dynamic Pressure and Temperature Instrumentation at the $90^{\circ}$ Location ALF (the $27^{\circ}$ Location is Similar but with Smaller Spacing Between the Combustor and LPT Probe Pairs).

\section{Data Acquisition and Analysis}

Two data systems were used to record the voltages from the dynamic temperature and pressure instrumentation. The first system, used as the primary recorder, was a 64-channel Dewetron Model 801 recorder. The second, used as a backup recorder, was a 48-channel Brüel \& Kjær Pulse system using eight 6-channel LAN-XI modules. Both systems feature 24-bit analog-to-digital conversion. Data was recorded at a sample rate of 10 to $20 \mathrm{kHz}$ for the Dewetron system, and $65.536 \mathrm{kHz}$ for the Pulse system. These sample rates were more than sufficient for this study. The primary goal was to resolve temperature fluctuations at the combustor exit up to $1000 \mathrm{~Hz}$ in order to cover the frequency range that is considered relevant to indirect combustion noise. The raw voltages from the thermocouples were recorded directly without amplification, because the amplifiers that were readily available in-house were found to introduce unacceptable electrical noise during system bench tests. Fortunately, the dynamic range of the recorders was sufficiently high that quantization noise was not significant over the frequency range of interest. The quantization level on the Dewetron system was found to be $0.03 \mu \mathrm{V}$, which corresponds to probe wire temperature fluctuations of less than $1^{\circ} \mathrm{F}$. The corresponding gas temperature fluctuations are larger than this, and depend upon a frequency dependent compensation gain factor. Currently, it is unknown what gas temperature fluctuation amplitudes need to be resolved, since it is not yet known what pressure magnitudes (i.e. indirect noise levels) are produced by the temperature fluctuations that convect through the turbine. However, it is likely that the temperature fluctuations of any practical importance were resolved in this test over the frequency range of interest. The electrical noise floor of the data systems and cabling also presents a limitation on the magnitude of temperature fluctuations that can be resolved. The electrical noise floor was found to be low, but set upper frequency limits on the 
temperature fluctuations that could be resolved in the combustor, inter-turbine duct, and mixer locations. In the combustor, this limit was well above $1000 \mathrm{~Hz}$. In the inter-turbine duct and mixer, where the temperature fluctuations are much smaller, this upper limit was approximately $500 \mathrm{~Hz}$ and $250 \mathrm{~Hz}$, respectively.

Measurements were acquired at four steady state operating conditions that span the range of power settings where combustion noise contributes to the aircraft noise levels. Data were acquired at $48 \%, 54 \%, 60 \%$, and $65 \%$ corrected fan speed (NFC). These specific speeds were chosen because extensive far field and phased array measurements had been previously acquired under the NASA EVNERT program at these settings. ${ }^{9}$ At each speed, the dynamic temperature and dynamic pressure measurements were simultaneously acquired for a record length of 70 seconds.

\section{A. Compensated Dynamic Temperature Spectra}

The primary objective of the test was to measure the dynamic gas temperature spectra in the core of the engine, particularly at the exit of the combustor. As mentioned previously, the dynamic gas temperature spectra are computed by applying measurement-derived compensation spectra to the measured dynamic wire temperature spectra. As a representative example, Figure 5 shows a five second clip of the measured dynamic wire temperature time histories for the five probes positioned along the left hand side of the engine ( $260^{\circ}$ ALF) at $48 \%$ NFC. The dynamic temperatures of the small and large wires are shown in blue and red, respectively. The mean temperature values have been subtracted from the time histories to better highlight the fluctuations. For a given probe, the temperature fluctuations of the small and large wires are observed to change roughly in unison, as expected. The small wire thermocouple, having a smaller diameter and less thermal mass, is heated and cooled more rapidly by the temperature fluctuations in the gas flow, and thus achieves larger extreme values. Taken to the limit, a vanishingly small thermocouple would have an even faster response and measure the actual temperature of the gas. It can be seen from the amplitude scales that the peak wire temperature fluctuations measured by the probes in the combustor are about an order of magnitude larger than the peak wire temperature fluctuations measured by the probes in the inter-turbine duct upstream of the LPT. And the peak wire temperature fluctuations measured by the probes in the inter-turbine duct upstream of the LPT are about twice as large as the peak wire temperature fluctuations measured in the mixer downstream of the LPT.

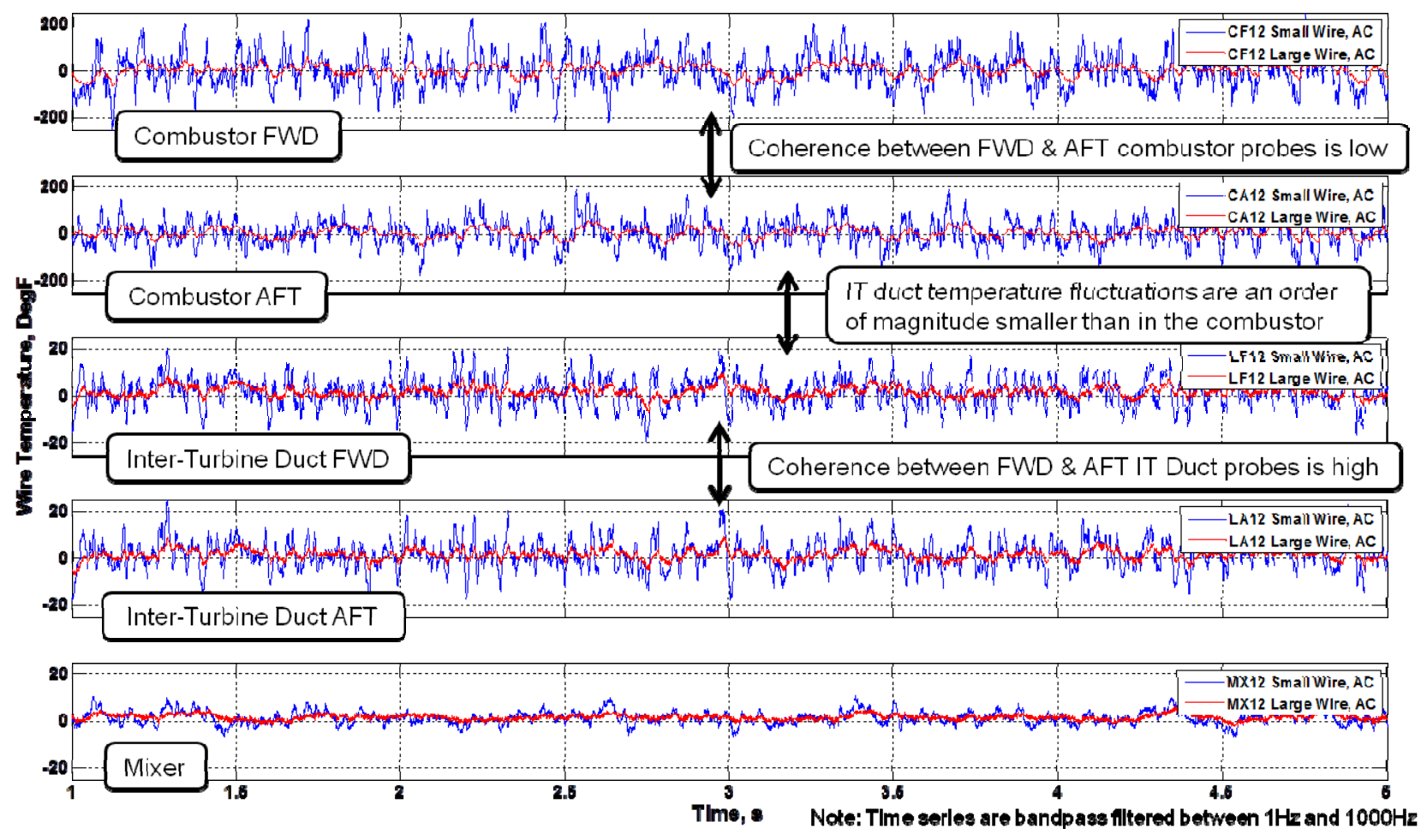

Figure 5. Dynamic Wire Temperatures Measured in the TECH977 Engine Core at 48\% NFC. 
The corresponding dynamic wire temperature spectra for the full 70 second time history recordings at $48 \%$ NFC are shown in Figure 6. The spectra at all measurement locations are observed to have smooth, broadband content. Also shown in the figure are the levels associated with the recording system noise floor. The combustor spectra are above the electronic noise floor to at least $1000 \mathrm{~Hz}$. In the inter-turbine duct, the small wire spectra approach the noise floor at about $500 \mathrm{~Hz}$, and in the mixer, the small wire spectra approach the noise floor at around $250 \mathrm{~Hz}$. The large wire spectra reach the noise floor at less than half those frequencies. Thus, the dynamic temperature spectra are only valid over a limited frequency range, which is dependent on location of the probe. From a practical perspective, this is not likely to be a limitation, since the electronic noise floor corresponds to very low fluctuating temperatures.
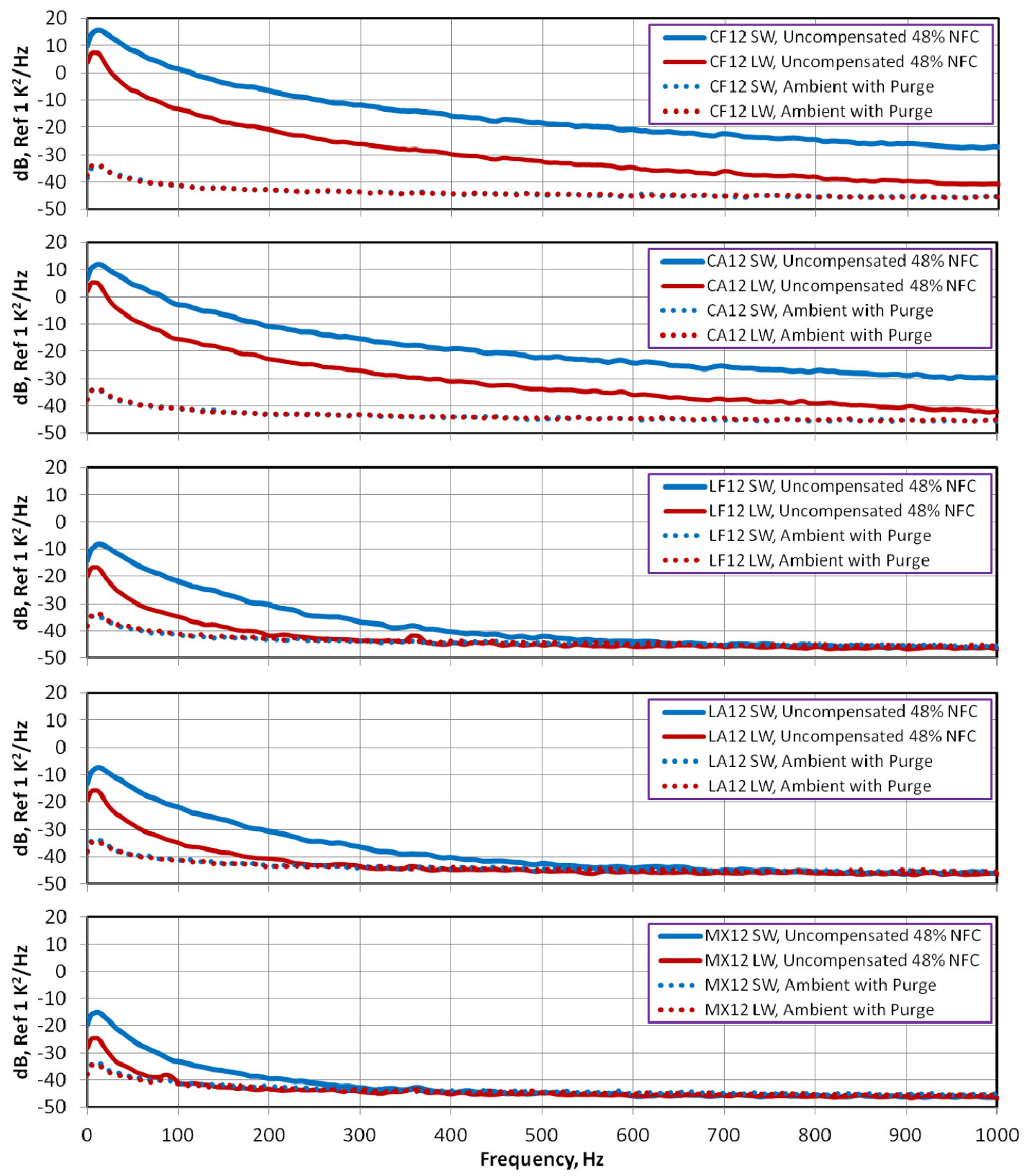

Figure 6. Wire Temperature Power Spectral Densities in the TECH977 Engine Core at $48 \%$ NFC. 
The measured frequency response between the large and small wires at a particular operating point is used to determine a compensation spectrum that is applied to the measured wire temperature spectrum to yield the temperature spectrum of the gas stream. The compensation spectrum is determined using the NASA software that models the convective and conductive heat transfer effects. The in-situ heat transfer calibration coefficient is determined using the measured transfer function between the large and small wires over a range of frequencies below $50 \mathrm{~Hz}$, and thus are unaffected by the electronic noise floor. A compensation spectrum can be computed for either the small wire or the large wire. The small wire spectra are used in the subsequent data reduction since they have a higher signal-to-noise ratio than the large wire and thus provide the widest frequency range for the compensated temperature spectra. Figure 7 provides an example of the compensation spectra that were computed for the small wires of the four combustor probes at $48 \%$ NFC. The gain corrections are shown as solid lines, and the phase corrections are shown as dotted lines. The gain corrections are significant, with corrections in the range of 25 $\mathrm{dB}$ being applied at $400 \mathrm{~Hz}$. Thus, the gas temperature fluctuations are substantially larger than the measured wire temperature fluctuations.

An example of applying the computed gain corrections to the measured wire temperature spectra is shown in Figure 8 , for the CA45 aft combustor probe at $48 \%$ NFC. Compensated temperature spectra are shown for both the small and large wire, where the small or large wire compensation spectrum is applied to the temperature spectrum measured by the small or large wire, respectively. Regardless of which approach is used, the compensated spectra are seen to be very similar, lending confidence in the data processing methodology. The compensated temperature spectrum represents the dynamic temperature spectra of the gas stream. This result is of fundamental interest to the indirect combustion noise problem, since it provides the scaling of the temperature fluctuations that convect through the mean flow gradients in the HPT and generate pressure fluctuations. It can be observed that the temperature spectrum at the exit of the combustor has wideband content, with a slow roll-off with frequency and no prominent peaks when examined on a narrowband basis. This observation might be useful for the indirect noise problem. Although the transfer function between temperature and pressure has not yet been determined for this engine, the lack of peaks in the temperature spectra suggests that the indirect combustion noise pressure spectra will not have noticeable peaks unless the conversion process itself favors a particular frequency range. Also, the simplicity of the spectral shape of the temperature fluctuations is an attractive feature from a computational modeling perspective.

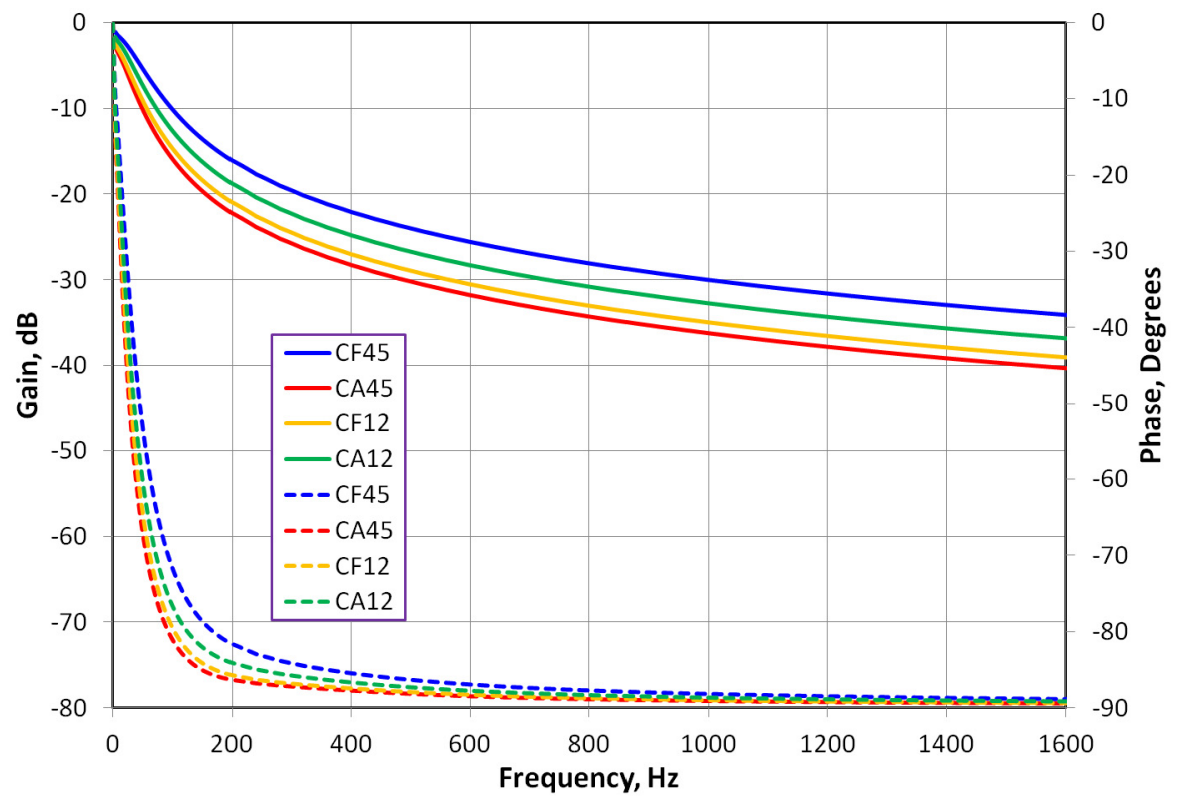

Figure 7. Small Wire Compensation Spectra for the Combustor Probes at $48 \%$ NFC. 


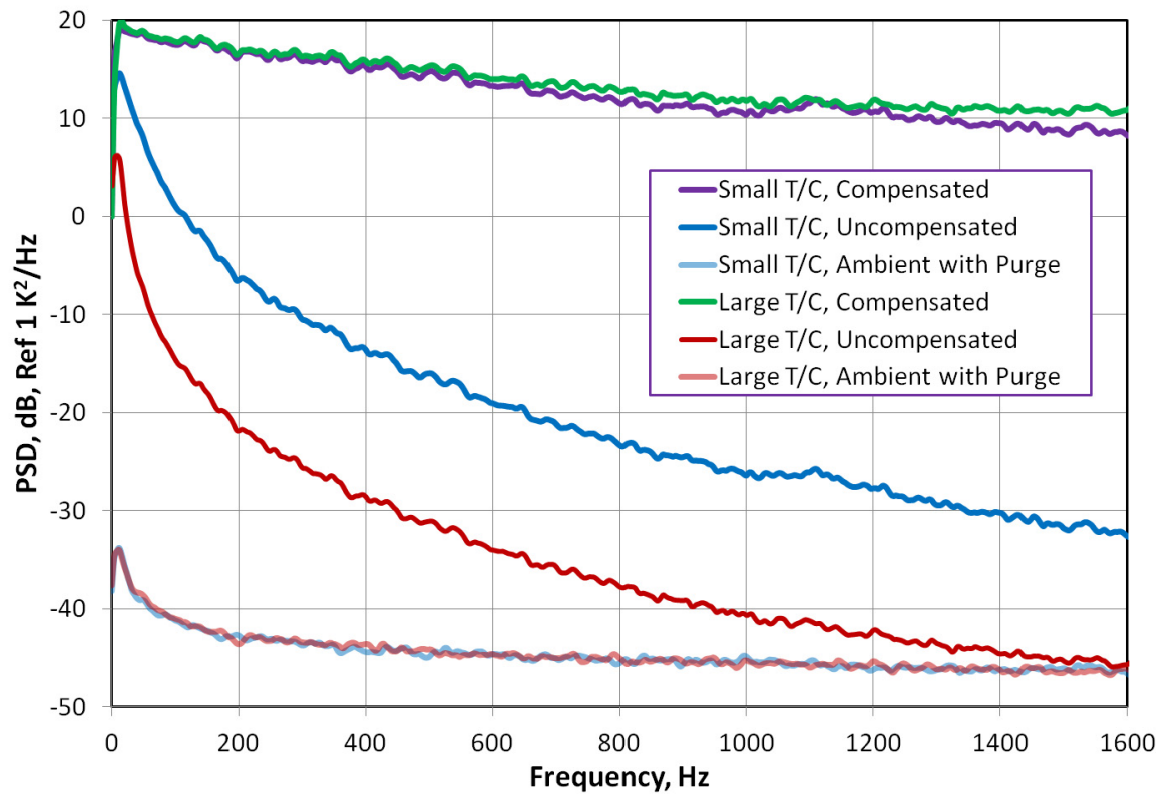

Figure 8. Compensated Temperature Spectrum for the CA45 Aft Combustor Probe at $48 \%$ NFC.

Figure 9 plots the compensated temperature spectra for the CA12 aft combustor probe at all four engine speeds, along with repeat measurements made at each of those speeds. The compensated temperature spectra are observed to be very repeatable, lending confidence in the repeatability of the thermodynamic state of the engine. The spectral levels do not change significantly over the tested range of speeds, which is perhaps surprising. This is also an important result, since it suggests that the spectral levels of the indirect combustion noise generated at the different speeds should not be substantially different, unless the change in the mean flow gradients at the different speeds significantly affects the noise generation process.

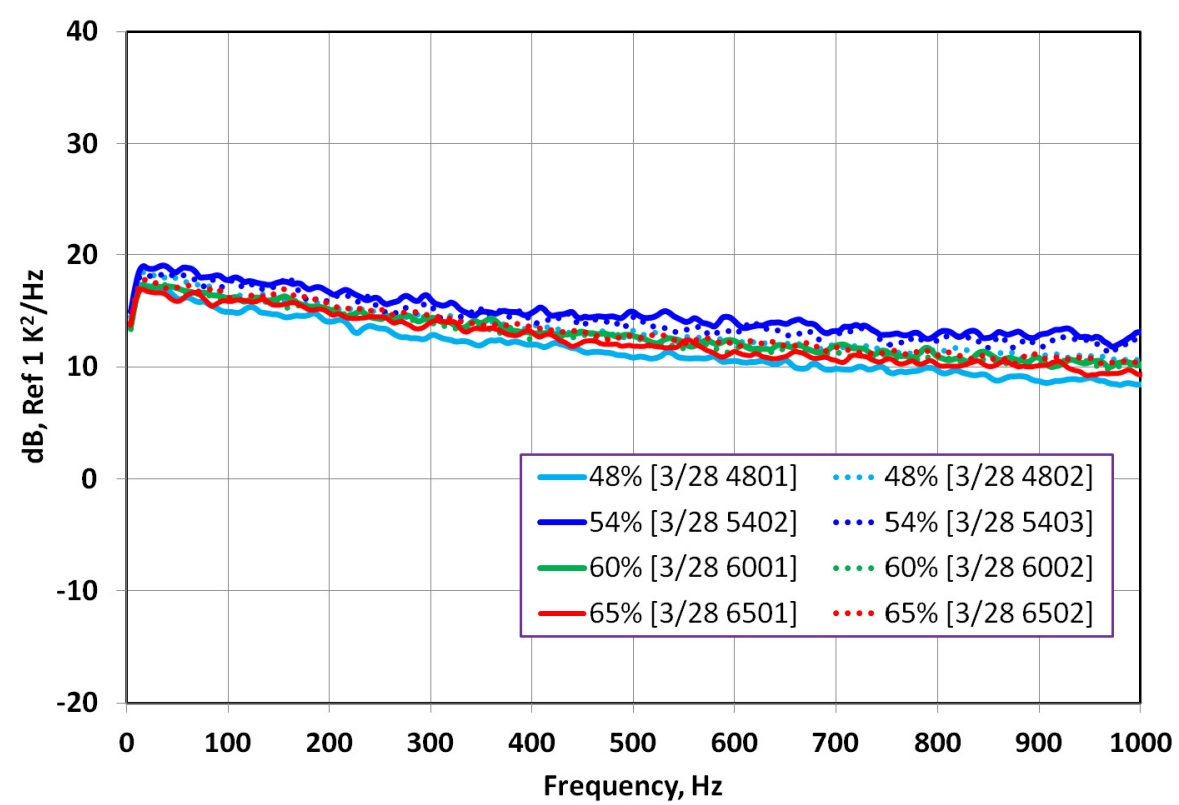

Figure 9. Small Wire Compensated Temperature Spectra for the CA12 Combustor Probe at Multiple Speeds. 
To get an intuitive feel for the magnitude of the compensated temperature fluctuations in the time domain (i.e. the actual fluctuating temperatures of the gas stream), an inverse Fourier transform can be applied to the (complex) compensated spectra to obtain a time domain representation of the compensated signal. This was accomplished as follows. First, the Fast Fourier Transform (FFT) of the entire small (or large) wire temperature time history was computed in a single block (typically 0.5 million data points). Second, the complex compensation spectrum of the small (or large) wire, which is computed by the software for a much smaller number of FFT points (e.g. 2048), was interpolated to the same number of points as the FFT in the first step. The interpolation presents no difficulty, since the compensation spectrum is very smooth. Third, the compensation spectrum was applied to the small (or large) wire time history FFT via complex division in the frequency domain. Finally, an inverse FFT is applied to the complex compensated spectrum to obtain the time domain representation of the compensated small (or large) wire signal. An important consideration when generating the time histories is that the compensation should not be applied to portions of the raw time history that are dominated by electrical noise. This was handled by only applying the compensation up to a certain maximum where the signal-to-noise ratio is known to be sufficiently high frequency (e.g., greater than $1000 \mathrm{~Hz}$ for the combustor data). The end result is a band-limited compensated time history, whose spectrum matches the compensated temperature spectrum of Figure 9 over the selected frequency range.

An example of this process is shown in Figure 10, which shows a short segment $(0.1 \mathrm{~s})$ of the compensated time history for the aft combustor probe CA12 at $48 \%$ NFC. The process described above was performed for both the small and large wires. It can be seen that the end result is nearly the same regardless of which wire is chosen for processing. Also shown in the figure are the uncompensated (as measured) wire temperature time histories. It is apparent that the temperature fluctuations of the compensated time histories, which represent the fluctuating gas temperature, are substantially larger than the measured fluctuating wire temperatures. What is perhaps surprising is the magnitude of the fluctuations. Fluctuations on the order of $\pm 500^{\circ} \mathrm{F}$ are quite common.

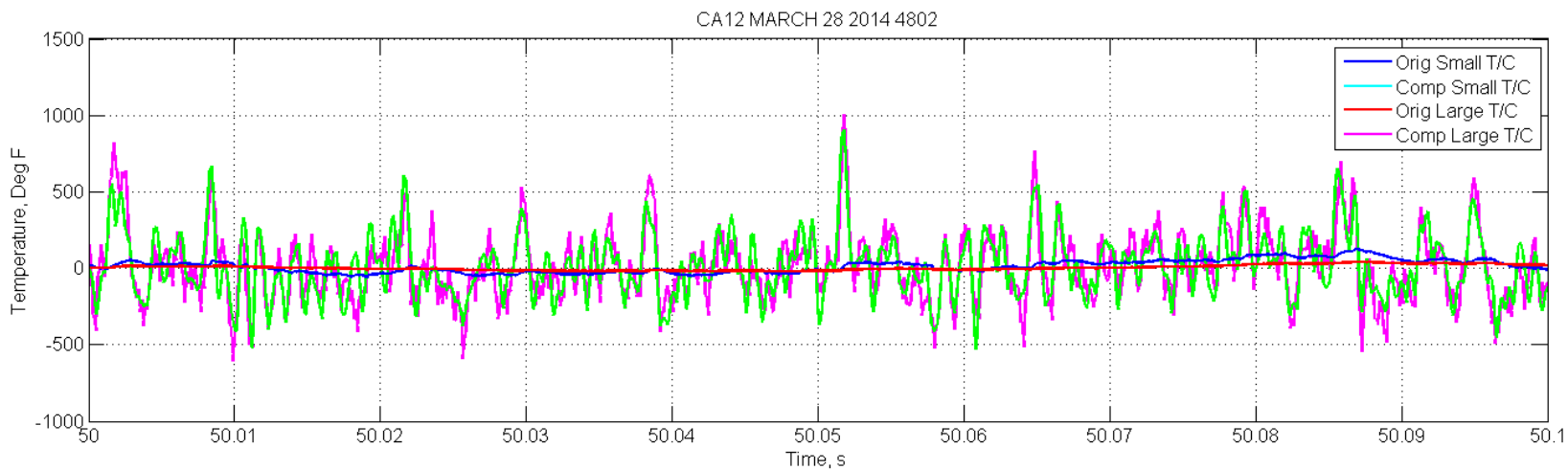

Figure 10. Small and Large Wire Compensated Time History Data for Combustor Probe CA12 at $48 \%$ NFC.

\section{B. Dynamic Pressure Spectra}

Dynamic pressure spectra were computed for all of the internal pressure transducers and external microphones. Figure 11 shows the power spectral density for all of the pressure transducers at $48 \%$ NFC. The spectral levels of the combustor and inter-turbine duct probes are similar and are examined in more detail in subsequent plots. The spectral amplitudes of the mixer probes are substantially below the levels of the combustor and inter-turbine duct probes and exhibit a more rapid falloff with frequency. Figure 12 plots of the power spectral density for all of the pressure transducers at $65 \%$ NFC. The most obvious difference is that the spectral levels for all the locations are around $5 \mathrm{~dB}$ higher than the levels at $48 \%$ NFC.

Figure 13 compares the spectra of all the probes in the combustor at $48 \%$ NFC. The spectra for the combustor sub-array probes, labeled PCE03, PCE07, PCE11, and PCE15, which are all stationed at the same axial plane but at different azimuthal clocking positions (see Figure 17), are all very similar. Slight undulations can be observed in the combustor spectra, and these are believed to correlate with resonances related to the combustor geometry. The forward combustor probe PCF45 is at nearly the same axial station as the sub-array probes and has a very similar spectrum as the sub-array probes. The other forward combustor probe PCF12 (located slightly aft of PCF45), and the two aft combustor probes PCA45 and PCA12 have similar spectra, but differences on the order several dB are apparent. Figure 14 compares the spectra of all of the probes in the combustor at $65 \%$ NFC. Similar conclusions can be made, with larger differences between the upstream probes and the downstream probes. 


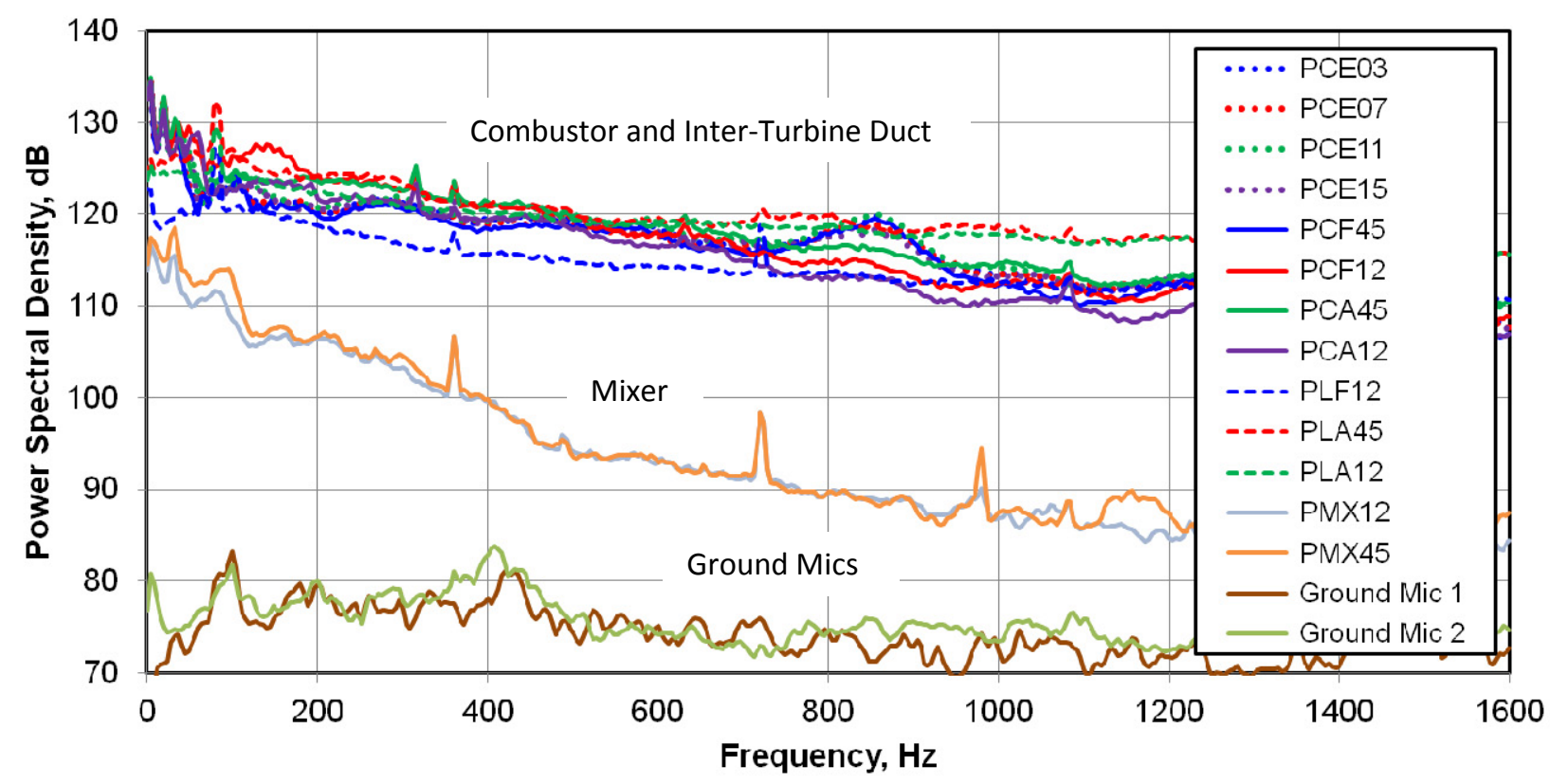

Figure 11. Measured Pressure Spectra for All Probes and Microphones at $48 \%$ Speed.

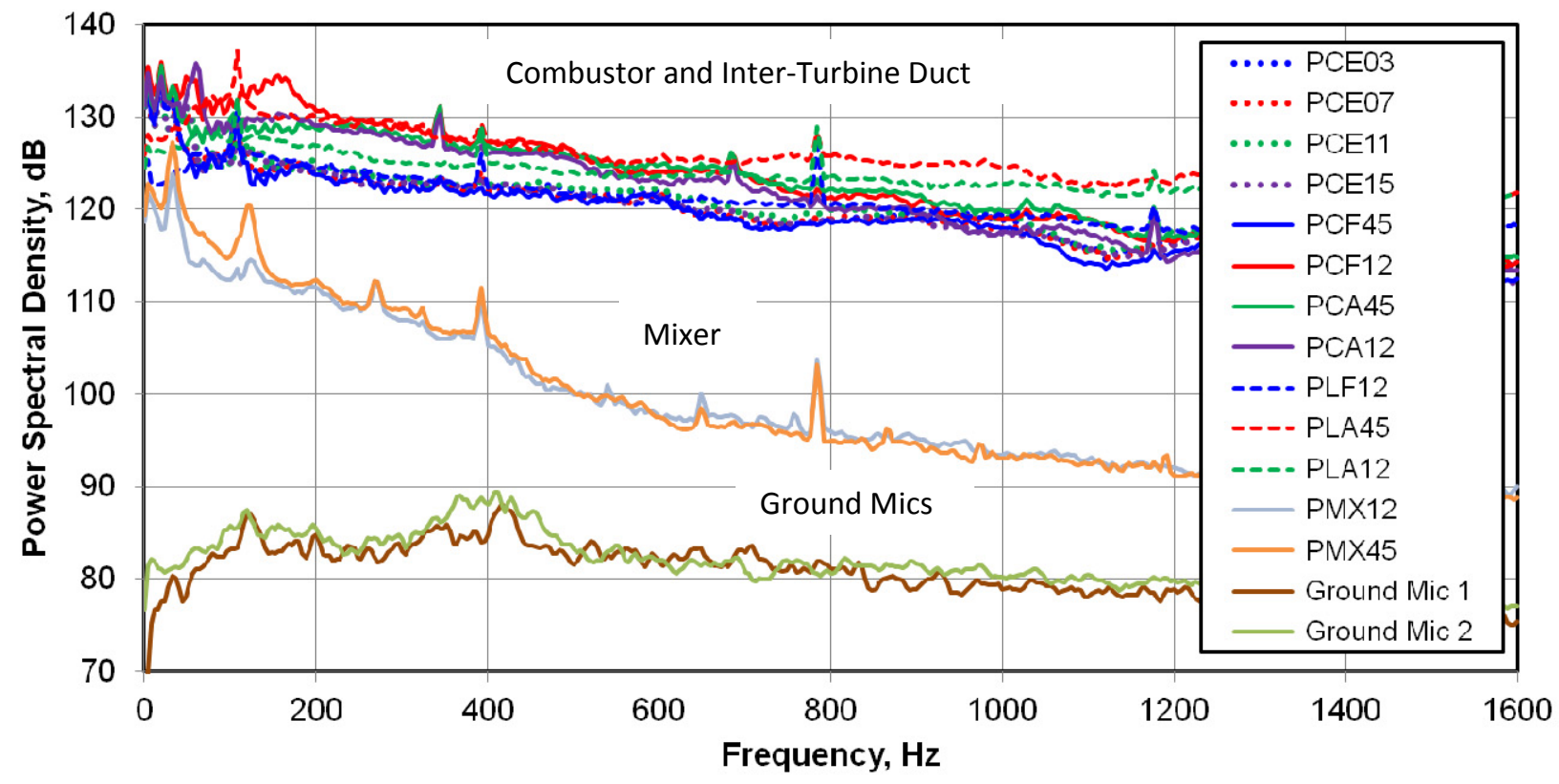

Figure 12. Measured Pressure Spectra for All Probes and Microphones at 65\% Speed. 


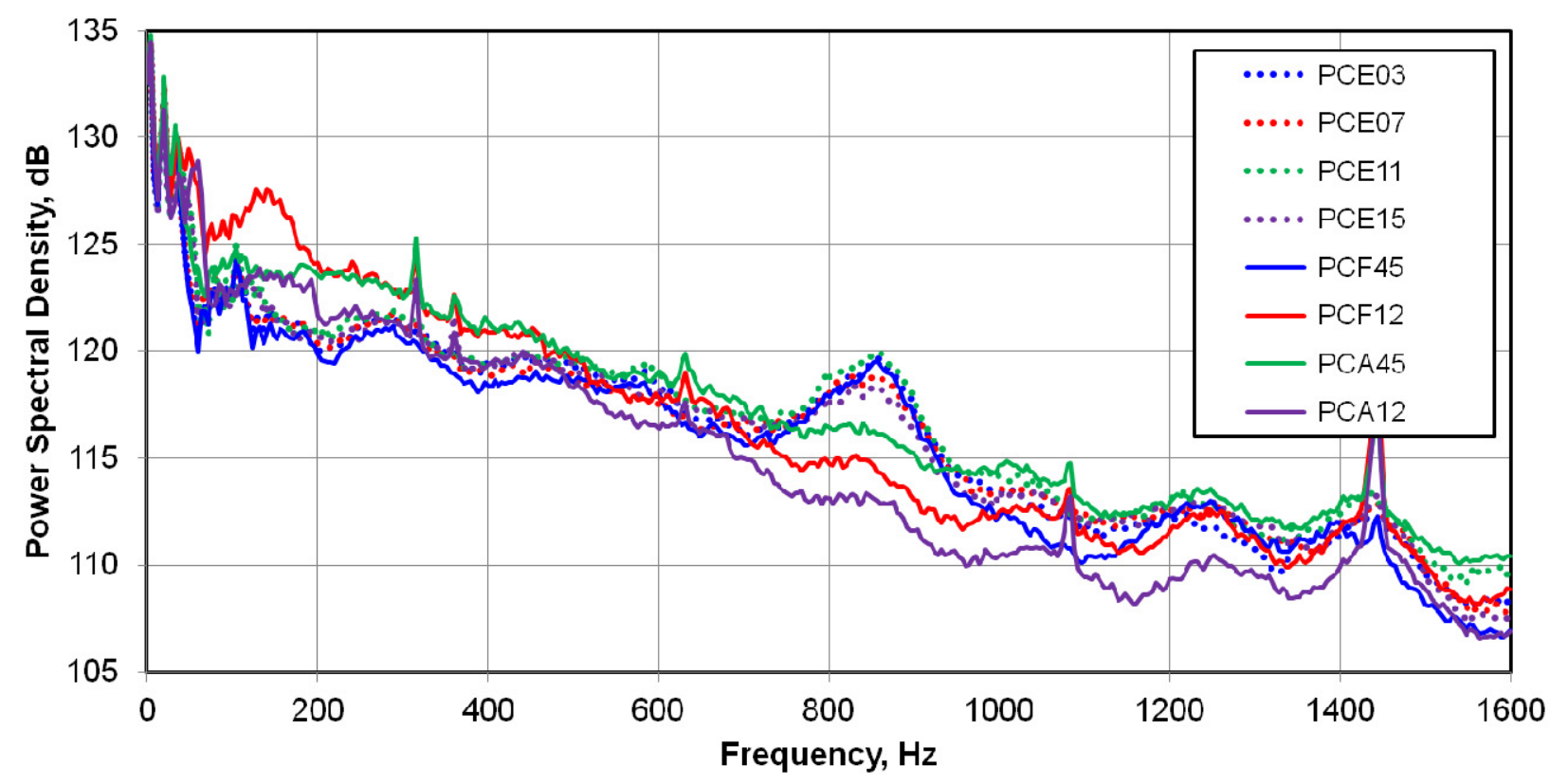

Figure 13. Measured Pressure Spectra for All Combustor Probes at 48\% Speed.

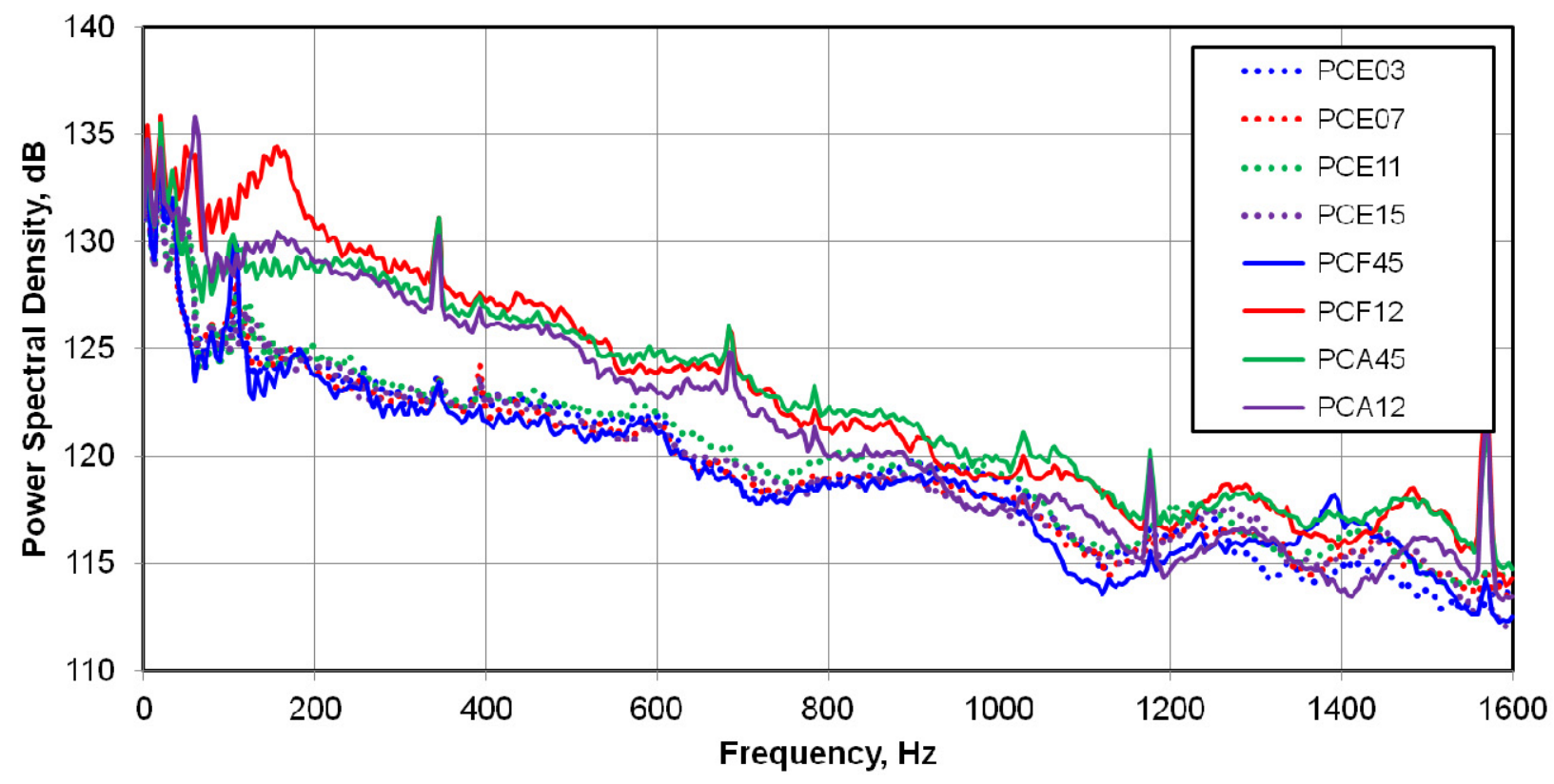

Figure 14. Measured Pressure Spectra for All Combustor Probes at 65\% Speed.

Figure 15 and Figure 16 compare the spectra of some of the pressure probes in the combustor with the pressure probes in the inter-turbine duct at $48 \%$ and $65 \%$ NFC. Surprisingly, the forward inter-turbine duct probe, PLF12, and the two aft inter-turbine duct probes PLA45 and PLA12, have generally similar spectral levels as the combustor probes. The two aft inter-turbine duct probes have similar levels. A comparison of the amplitude and shape of the 
pressure spectra for probes stationed upstream and downstream of the HPT does not yield simple or straightforward conclusions regarding the generation of indirect combustion noise. There are no features in the spectra that change dramatically. For example, there is no obvious broadband peak that appears in the pressure spectra upon crossing the HPT. And the levels measured in the inter-turbine duct tend to bracket or overlap the levels measured in the combustor. This makes it challenging to draw any conclusions based on spectral comparisons alone.

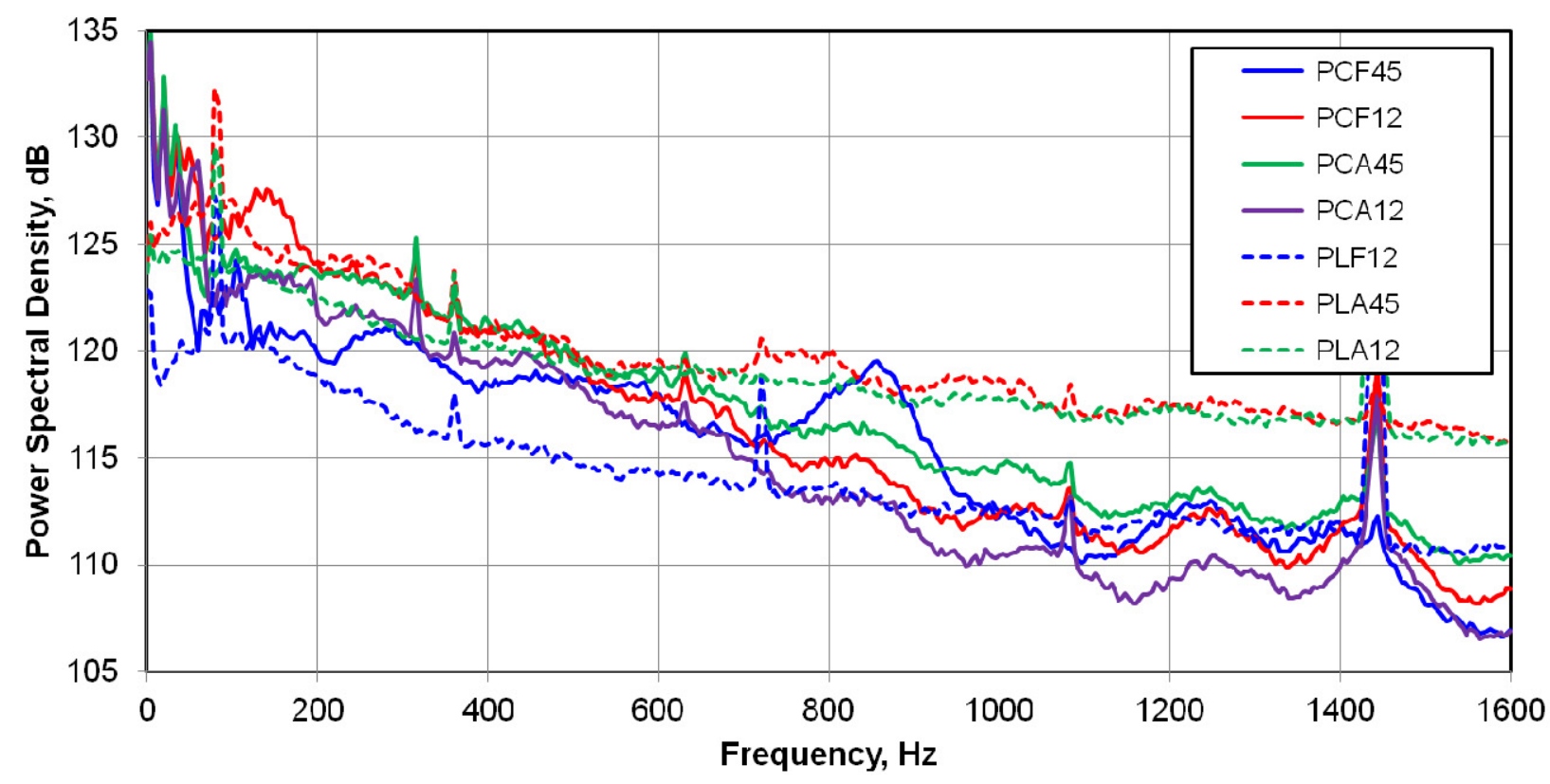

Figure 15. Measured Pressure Spectra for Several Combustor and Inter-Turbine Duct Probes at 48\% Speed.

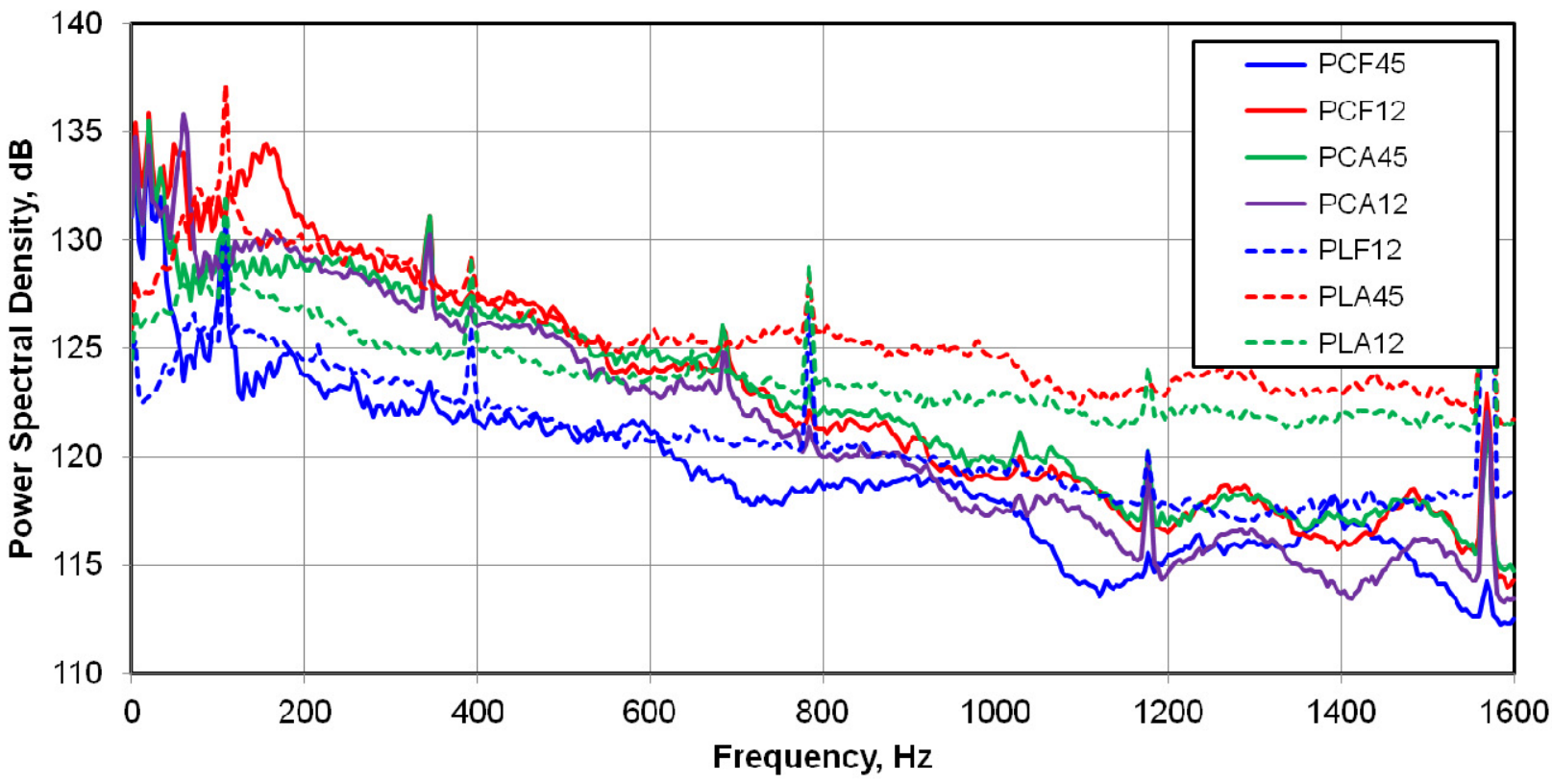

Figure 16. Measured Pressure Spectra for Several Combustor and Inter-Turbine Duct Probes at 65\% Speed. 


\section{Combustor Modal Analysis}

An array of 4 equally spaced dynamic pressure probes was located in the forward part of the combustor. The array is a subset of a larger 16 probe array that was previously used during the NASA EVNERT program to measure the modal content of the acoustic field inside this combustor. The primary purpose of the sub-array was to provide a confirmation that the acoustic levels and modal content were not appreciably changed by the hardware modifications made to accommodate the temperature probes. Figure 17 shows the locations of the circumferential sub-array of pressure probes on the current Dynamic Gas Temperature Measurement System (DGTMS) test, relative to the original set of 16 probes on the EVNERT test. Figure 18 presents a comparison of the circumferential mode decomposition at $48 \%$ NFC, computed using just the four sensors in the sub-array, between the 2008 NASA EVNERT test and for the current test. The spectral amplitudes and modal content were found to be essentially the same, although a slight modulation of the modal amplitudes was observed in the current test. It can be seen that the plane wave is dominant in the combustor region up to about $500 \mathrm{~Hz}$. Between $500 \mathrm{~Hz}$ and $1000 \mathrm{~Hz}$, the $m=-1$ and $m=+1$ modes are dominant with essentially equal amplitude. Between $1000 \mathrm{~Hz}$ and $1700 \mathrm{~Hz}$, the $m=-2$ and $m=$ +2 modes are dominant, although with only four sensors these modes are aliased together and cannot be independently resolved. In the NASA EVNERT test these two modes were found to have nearly equal amplitude.

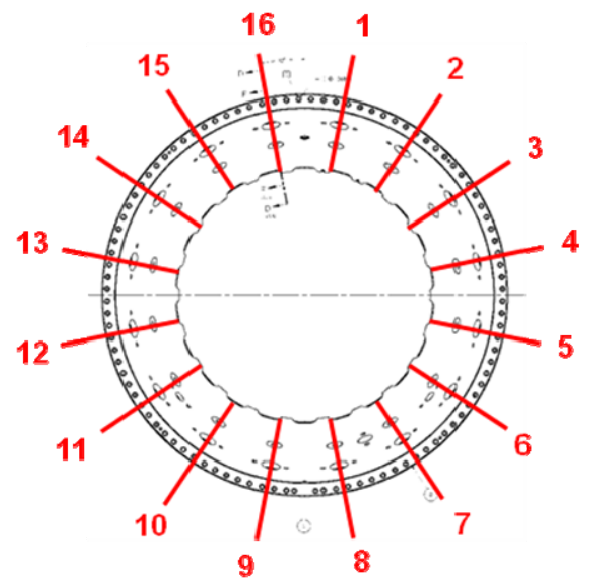

EVNERT (ALF)

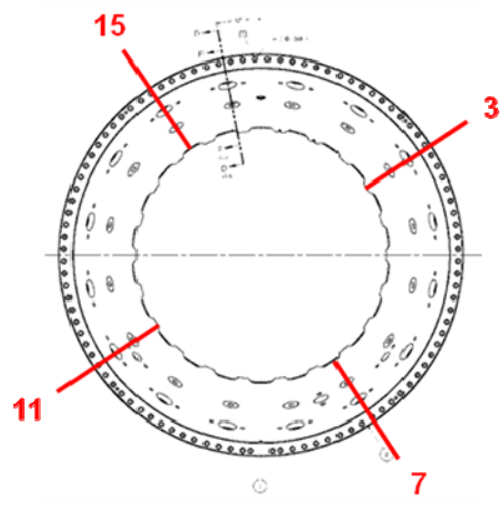

DGTMS (ALF)

Figure 17. A Sub-Array of 4 Equally Spaced Pressure Transducers Was Used to Confirm the Modal Content.
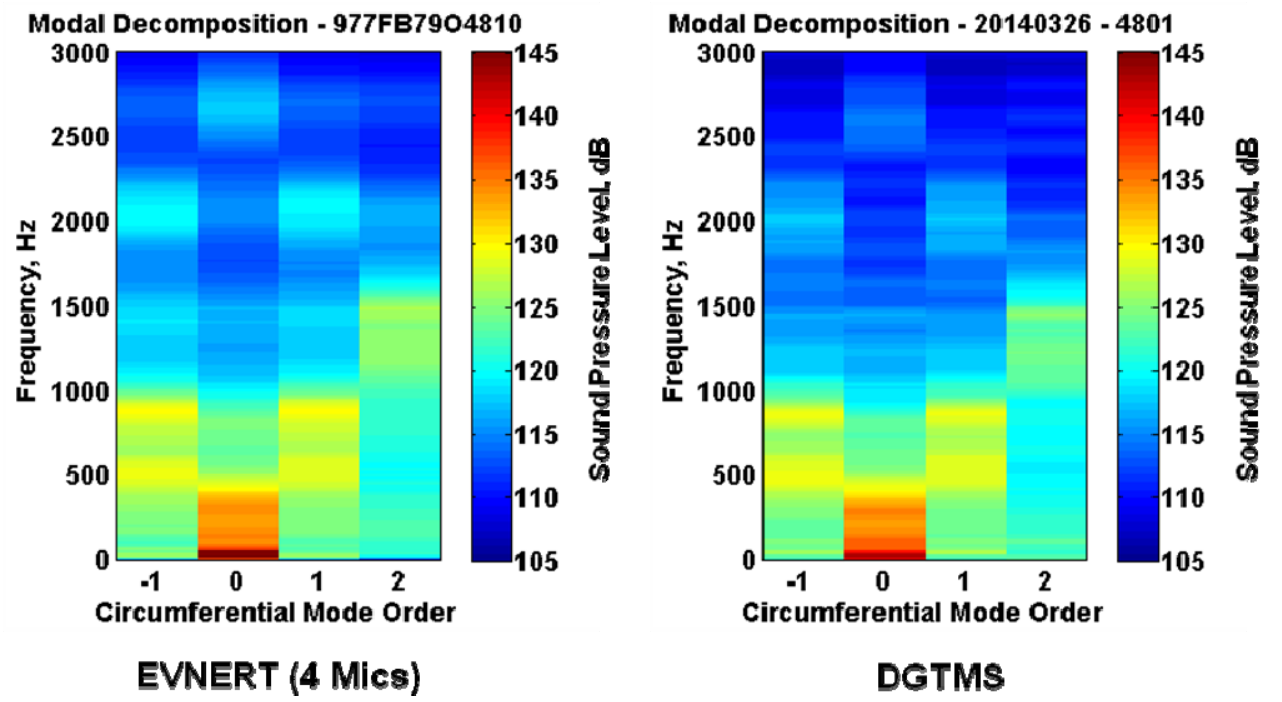

Figure 18. Combustor Modal Decomposition at $48 \%$ NFC.

14

American Institute of Aeronautics and Astronautics 


\section{Temperature and Pressure Cross-Spectral Analysis}

Cross-spectral analyses between temperatures measured at different locations can provide additional insights into the behavior of the temperature fluctuations, such as eddy convection speeds. Figure 19 shows the coherence between the upstream and downstream probes in the combustor and in the inter-turbine duct at $48 \% \mathrm{NFC}$. The coherence between the two pairs of probes in the combustor is quite low. A review of the mean temperature data revealed that the mean temperature at the forward location was around $700^{\circ} \mathrm{F}$ higher than the mean temperature at the aft locations, suggesting that the forward probe was located near the flame zone and that very substantial mixing occurs between the two locations, which would explain the low coherence. As a result, it is difficult to determine convection speeds of the temperature fluctuations entering the HPT. On the other hand, in the inter-turbine duct, where less mixing occurs, the coherence between upstream and downstream temperature probe signals is very high, and it is possible to estimate convection speeds. The cross spectral phases between the small wire signals from the upstream and downstream probes on either side of the inter-turbine duct are presented in Figure 20. The phase shows a predominantly linear behavior over a frequency range up to $500 \mathrm{~Hz}$. A linear fit through the data can be made, and a time delay can be computed from the fitted slope via $\tau=(d \theta / d f) / 360^{\circ}$. The average computed time delay is $0.15 \mathrm{~ms}$ for the probes on the right hand side of the engine which have a $1.3^{\prime \prime}$ spacing, and $0.09 \mathrm{~ms}$ for the probes on the left hand side of the engine which have a 1 " spacing. These measured time delays are very close to the predicted values computed using the engine cycle estimated flow velocity and the sensor spacing, namely $0.13 \mathrm{~ms}$ and $0.1 \mathrm{~ms}$ for the two pairs, respectively. This confirms that the temperature fluctuations are simply convected by the mean flow in this location.
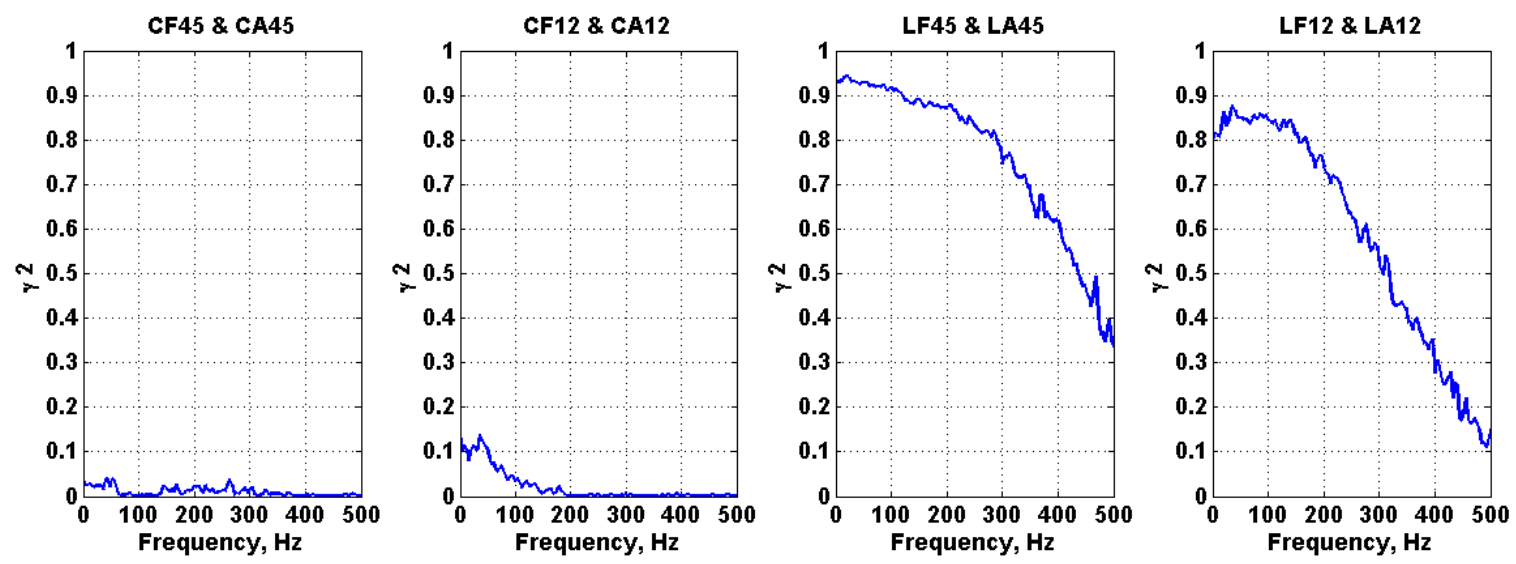

Figure 19. Coherence Measured Between Upstream and Downstream Temperature Probes at 48\% NFC.
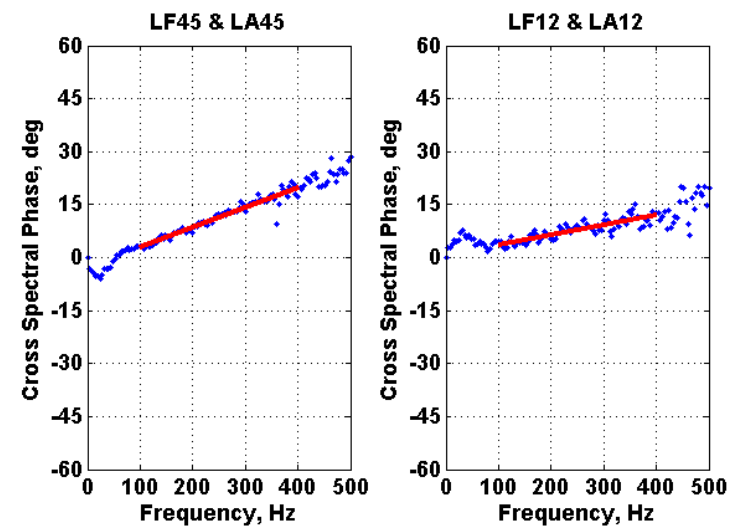

Figure 20. Cross-Spectral Phase Between Upstream and Downstream Small Wire Thermocouple Pairs in the Inter-Turbine Duct at 48\% NFC. 


\section{Conclusion}

A database of dynamic temperature and pressure measurements was acquired in the core of a Honeywell TECH977 propulsion engine. Dynamic gas temperature spectra and time histories were computed from the measured thermocouple wire signals using a compensation procedure developed in previous NASA programs. Compensated temperature spectra and time histories were generated up to a frequency range of $1000 \mathrm{~Hz}$ in the combustor, $500 \mathrm{~Hz}$ in the ITD, and $250 \mathrm{~Hz}$ in the mixer. The measurements revealed that the temperature fluctuations measured upstream of the HPT are an order of magnitude larger than those measured upstream of the LPT. The dynamic temperature fluctuations did not change substantially with engine speed. Cross spectral measurements between upstream and downstream pairs of probes upstream of the LPT confirmed that the temperature fluctuations were convected by the mean flow. These measurements will enable further exploration of indirect combustion noise generation in a realistic application, and will also provide quantitative inputs necessary for computational models.

\section{Acknowledgments}

The Acoustic Database for Core Noise Program was sponsored by the NASA Fundamental Aeronautics Program, Fixed-Wing Project, under Contract No. NNC11TA40T. Honeywell would like to thank the staff of the NASA Glenn Research Center for their substantial support and technical insights.

\section{References}

${ }^{1}$ Miles, J.H., Wasserbauer, C.A., and Krejsa, E.A., "Cross Spectra between Temperature and Pressure in a Constant Area Duct Downstream of a Combustor," NASA TM 83351, 1983.

${ }^{2}$ Miles, J.H., Wasserbauer, C.A., and Krejsa, E.A., "Cross Spectra between Temperature and Pressure in a Constant Area Duct Downstream of a Hydrogen Fueled Combustor,” NASA TM 83463, 1983.

${ }^{3}$ Elmore, D.L., Robinson, W.W, and Watkins, W.B., "Dynamic Gas Temperature Measurement System, Volume I Technical Efforts,” United Technologies, Pratt \& Whitney Division, NASA CR-168267, 1983.

${ }^{4}$ Purpura, P. T., "Dynamic Gas Temperature Measurement System, Volume II - Operation and Program Manual," United Technologies, Pratt \& Whitney Division, NASA CR-168267, 1983.

${ }^{5}$ Elmore, D.L., Robinson, W.W, and Watkins, W.B., "Further Development of the Dynamic Gas Temperature Measurement System, Volume I - Technical Efforts,” United Technologies, Pratt \& Whitney Division, NASA CR-179513, 1986.

${ }^{6}$ Stocks, D.R. and Elmore, D.L., "Further Development of the Dynamic Gas Temperature Measurement System, Volume II - Computer Program User's Manual,” United Technologies, Pratt \& Whitney Division, NASA CR-179513, 1986.

${ }^{7}$ Fralick, G.C., Oberle, L.G., and Greer, L.C. III, "Dynamic Gas Temperature Measurements Using a Personal Computer for Data Acquisition and Reduction," NASA TM106119, 1993.

${ }^{8}$ Royalty, C. and Schuster, B., "Noise from a Turbofan Engine Without a Fan from the Engine Validation of Noise and Emissions Reduction Technology Program, AIAA 2008-2810.

${ }^{9}$ Weir, D., "Engine Validation of Noise and Emission Reduction Technology Phase I," NASA CR 2008-215225.

${ }^{10}$ Weir, D. S. and Mendoza, J. M., "Baseline Noise Measurements from the Engine Validation of Noise and Emissions Reduction Technology Program," AIAA 2008-2807, 14 ${ }^{\text {th }}$ AIAA/CEAS Aeroacoustics Conference, Vancouver, BC, Canada, 5-7 May 2008. 